\title{
Video Tutorials in Mathematics Education for Engineering Students
}

\section{Ms. Franziska Dorothea Wehner, Technische Universität Darmstadt}

Franziska D. Wehner graduated from Heidelberg University with a M.Sc. in Psychology in 2014. She is currently a research associate in the Institute for Psychology at Technische Universität Darmstadt. Her research interests focus on the evaluation and improvement of higher education. 


\section{Video Tutorials in Mathematics Education for Engineering Students}

Introduction

Engineering students often struggle with mathematics. For example, in Germany, introductory mathematics courses often have high failure rates and are considered to be a difficult hurdle for engineering students ${ }^{1}$. Similar problems have been reported in other countries such as the U.S. ${ }^{2}$. Thus, it is essential to search for ways to provide engineering students with the support they need to succeed in mathematics. In the last decades, various online learning resources have enriched mathematics education. One example are video tutorials, i.e. screencasts in which a (typically handwritten) solution of a mathematics problem is explained step by step in audio comments ${ }^{3}$.

In order to effectively use and improve such video tutorials, it is important to know more about how students use such tutorials, and their satisfaction with them. However, to the author's knowledge, only few studies have yet focused on video tutorials in mathematics higher education ${ }^{3}$ and even fewer have specifically focused on engineering students (for an exception, see ${ }^{4}$ ). Existing studies suggest that students use video tutorials for various purposes, including assignments, comprehension difficulties, content review and exam or test preparation $^{3,5}$. Furthermore, several studies showed high satisfaction with video tutorials among students ${ }^{5,6}$, who appreciate for example the opportunity to receive explanations and stepwise solutions, and the flexibility concerning time, location and pace of studying $5,7,8$. Concerning the frequency of use of video tutorials, there is contradicting evidence. Whereas many studies suggest that the majority of students uses video tutorials at least to some extent ${ }^{5}$, 6 , and that, compared with other resources, they are among the resources used most often by students in mathematics courses ${ }^{4}$, some studies found only low rates of use ${ }^{8}$.

The current study aims to increase knowledge on students' use of and satisfaction with video tutorials in mathematics courses and thus, to contribute to filling a relative void in the literature concerning these topics and to improving mathematics higher education for engineering students. This paper is part of a larger study examining several aspects of engineering students' self-regulated learning in mathematics courses (e.g. students' use of various learning resources as well as their learning strategies, achievement goals and attributions). However, the focus of the current paper will be on answering the following research questions:

1. How do engineering students use video tutorials in mathematics courses?

2. How frequently do engineering students use video tutorials in mathematics courses?

3. How helpful do engineering students find video tutorials in mathematics courses? 
The study was conducted in an advanced calculus course for engineering students at a technical university in Germany. Important contents were differential equations and complex analysis. In the first part of the course, basic existence and uniqueness theorems for solutions to general ordinary differential equations and systems were introduced. Moreover, students were taught how to solve a number of specific nonlinear equations. The second part of the course dealt with the theory of holomorphic functions. Applications of Cauchy's integral formula were discussed. Two courses on analysis and linear algebra are prerequisites for the course.

Besides a lecture which was held twice a week, students had the opportunity to visit tutorial groups and to use various online learning resources, in particular lecture recordings, lecture slides, lecture notes and video tutorials. Online learning resources were made available to students via an electronic learning platform. The course and its evaluation were part of the project "Competence Development through Interdisciplinary and International Cooperation from the Start", which is funded as part of the Teaching Quality Pact by the German Federal Ministry of Education and Research (Grant 01PL16048). Responsibility for the contents of this publication rests with the author.

Overall, 12 videos were available for the course. The videos had a duration from about 7 to 18 minutes (mean duration 11 minutes and 44 seconds). They were constructed as slides on which the task as well as relevant theorems and formulas were written a priori with a computer. The tasks were then solved in handwriting. An audio commentary accompanied the slides in which the task, the theorems and formulas and all steps of problem solving were commented and explained.

For example, one video dealt with the Picard-Lindelöf theorem. In the video, two tasks were solved, one of which will be presented in the following as an example for the method of problem solving.

The video starts by presenting the following task:

Given is the initial value problem

$$
\left\{\begin{array}{c}
y^{\prime}(t)=1+t+y(t)+t y(t), t \in(0,1) \\
y(0)=1
\end{array}\right.
$$

Find a function $f$ such that the differential equation has the form $y^{\prime}(t)=f(t, y(t))$, and show that the initial value problem has a unique solution.

In order to solve this problem, the Picard-Lindelöf theorem is used and therefore introduced right at the beginning. 
In the next step, the narrator starts by identifying the function $f$ as

$$
f(t, y)=1+t+y+t y .
$$

Referring back to the theorem, the narrator then identifies the first condition of the PicardLindelöf theorem

$f$ continuous

The narrator points out that this function is a polynomial function and thus, the first condition is fulfilled. Then, the narrator checks the Lipschitz continuity, which is the second condition of the Picard-Lindelöf theorem, by writing down the following:

For $t \in(0,1), u_{1}, u_{2} \in \mathbb{R}$ it holds

$$
\left|f\left(t, u_{1}\right)-f\left(t, u_{2}\right)\right|=\left|1+t+u_{1}+t u_{1}-\left(1+t+u_{2}+t u_{2}\right)\right|
$$

The narrator continues by reducing the right part of the equation.

$$
\begin{aligned}
\left|f\left(t, u_{1}\right)-f\left(t, u_{2}\right)\right| & =\left|u_{1}+t u_{1}-u_{2}-t u_{2}\right| \\
& =\left|u_{1}(1+t)-u_{2}(1+t)\right| \\
& =|1+t| \times\left|u_{1}-u_{2}\right|
\end{aligned}
$$

Following this, the narrator explains that since $t \in(0,1)$, it holds

$$
\left|f\left(t, u_{1}\right)-f\left(t, u_{2}\right)\right|=|\leq 2| u_{1}-u_{2} \mid
$$

Based on this, the narrator points out that the second condition is also fulfilled, and concludes

From this the existence of a unique solution follows from the Picard-Lindelöf theorem with the Lipschitz constant $M=2$.

\section{Method}

A total of 27 students took part in the study. $77.8 \%(N=21)$ of the participants were male, and $22.2 \%(N=6)$ were female. Participants' age ranged from 18 to 29 . The majority were sophomores $(74.1 \%)$. A comparison with national statistics showed that the sample was representative for engineering students in Germany concerning gender, but that students who 
had achieved their university-entrance diploma in another country ( 3 students, $11,1 \%$ of the sample) were potentially underrepresented ${ }^{9}$.

To answer the research questions, semi-structured interviews with an average duration of about 30 minutes (average duration of the recordings was 25 minutes and 55 seconds) were conducted. The interviews followed a guideline, but the interviewer was free to adapt the guideline to the course of the interview. The audio recordings of the interviews were transcribed in verbatim using transcription rules adapted from other researchers ${ }^{10,11}$. For analyzing the anonymized interview transcripts, a method for qualitative content analysis ${ }^{12}$ provided orientation, which follows a deductive-inductive approach and thus allows one to acknowledge pre-existing knowledge and assumptions without ignoring the individual contributions of the participants. First, main categories were created based on research and interview questions. Among the main categories, there were three with relevance to the current study as they referred to a) the way students used different learning resources, b) the frequency with which students used these resources, and c) students' satisfaction with these resources. For all categories, subcategories covering different learning resources with one referring specifically to video tutorials were created a priori. After this, all transcripts were read and summarized by the author. Then, the initial coding frame was applied to three interviews and revised where needed. In the next step, seven interviews were coded by two coders. Codings were compared and where deviating, a common coding was found through discussion. Following this, the author coded the remaining interviews (including those used for initial testing of the coding frame). Then, subcategories were created inductively by inspecting the codings assigned to each category. Relevant for the current study, the inductive generation of subcategories for the category assessing students' use of video tutorials led to the identification of two major subcategories (each being divided into further subcategories) covering the purposes for which students used video tutorials and the reasons students gave for not using them. For the categories covering the frequency of use and students' satisfaction with the video tutorials, evaluative subcategories were defined and participants were assigned to the subcategories jointly by two coders based on all codings available. After all codings had been reassigned to the inductively generated categories, additional checks were made to ensure that all codings relevant to the respective categories had been included. Demographic information was collected with a questionnaire and analyzed with descriptive statistics.

Results

With respect to research question 1 , the analysis showed that students used video tutorials mainly for three purposes: for exam preparation, to achieve understanding of topics and problem solving methods (through their demonstration) and when working on mathematics problems (e.g. to check solutions or when experiencing difficulties). As can be seen in Table 1 and Figure 1, among these, exam preparation was the most important reason for using the video tutorials. With respect to this category, further subcategories were generated which allowed to describe in more detail, for which purposes students used video tutorials. The results showed that besides generally using video tutorials for exam preparation $(N=5$ 
students, see Table 1 for exemplary statement), 5 students specifically mentioned referring to video tutorials during exam preparation to receive explanations and see demonstrations of problem solving methods and mathematics problems. An exemplary statement for this subcategory is: "And yes, on the other hand (...) they [the video tutorials] explain sample mathematics problem very well one time. (...) And (...) yes, this was (...) very useful". 4 students used video tutorials to refresh their memory concerning topics and problem solving methods. For this subcategory, an exemplary statement is "but then during the exam (....) phase, when it is again about recapitulating, that one recalls it again, this is definitively helpful, if someone then again demonstrates the calculation quickly and one then also simply remembers "Ah, that's right, it was like this". (...)". 3 students reported using video tutorials because they provided solutions to mathematics problems, as is expressed in this exemplary statement: "then in the semester $X Y$, videos for the practice problems during exam preparation were uploaded, which was really helpful since we did not have solutions for them. And then, this were the solutions to some problems. That was really helpful.". Lastly, 2 students mentioned using video tutorials because they contained important topics. An exemplary statement for this subcategory is: "I have used this [the video tutorials] (...) increasingly. And I think this is very good, too, also now with regard to (...) yes, concerning the exam. Because (...) I just think, the things, which have been deepened again there, they just are really important."

\begin{tabular}{|c|c|c|}
\hline $\begin{array}{l}\text { Purpose for using } \\
\text { video tutorials }\end{array}$ & $N$ & Exemplary statement \\
\hline exam preparation & 12 & $\begin{array}{c}\text { "I have used this [the video tutorials] more in the semester } \\
\text { XY (...) for exam preparation in addition," }\end{array}$ \\
\hline $\begin{array}{l}\text { introduction to } \\
\text { problem solving } \\
\text { methods }\end{array}$ & 10 & $\begin{array}{c}\text { "to simply understand the scheme, I use it [the video tutorial] } \\
\text { then." }\end{array}$ \\
\hline $\begin{array}{l}\text { assignment } \\
\text { assistance }\end{array}$ & 6 & $\begin{array}{l}\text { "Yes simply (...) always before I started with the (...) } \\
\text { assignments, to just again (...) so it then usually was a } \\
\text { problem type, which then also turned up in the assignments. } \\
\text { (I: ok) (...) And then one could for example, I partially did the } \\
\text { steps for my assignment in parallel and then (...) followed it } \\
\text { [the video tutorial] and so." }\end{array}$ \\
\hline other reasons & 2 & $\begin{array}{l}\text { "I quickly look through and (...) simply, I want to know if (...) } \\
\text { XY said something special about it or not. Otherwise I look it } \\
\text { [the video tutorials] through very quickly and (...) if I see } \\
\text { nothing new then (...) that is yes that was it already." }\end{array}$ \\
\hline
\end{tabular}

Table 1. Purposes for using video tutorials. Codings could be assigned to several categories. $N=$ number of documents in which the category was coded, $\mathrm{I}=$ interviewer, $(\ldots)=$ pause, $\mathrm{XY}=$ anonymized. 


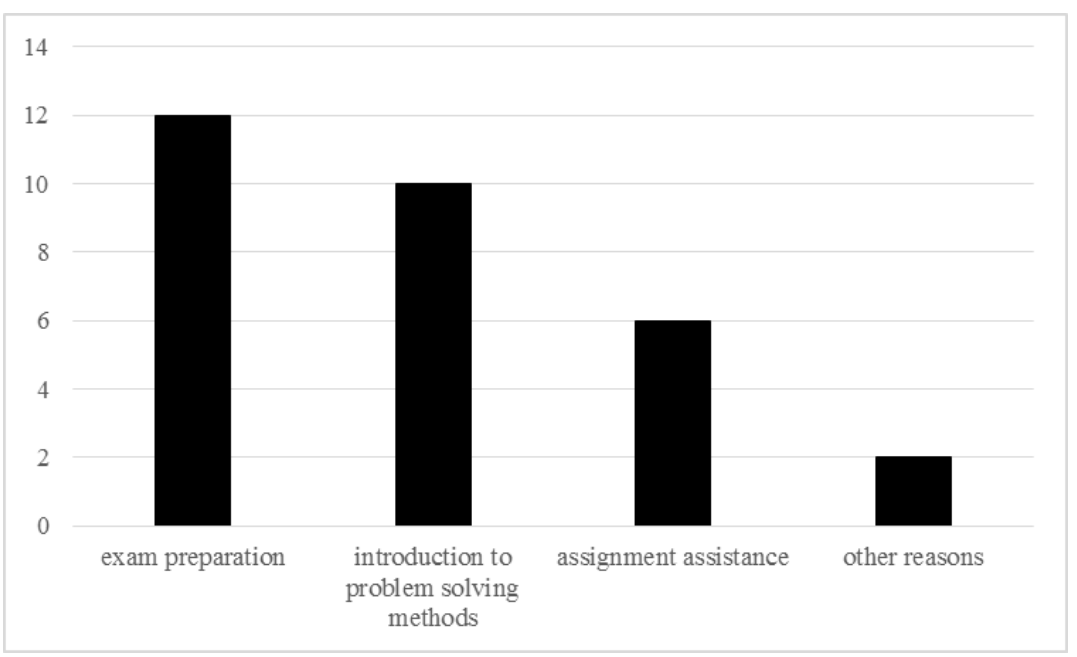

Figure 1. Purposes for using video tutorials. Depicted is the number of participants assigned to the subcategories. Participants could be assigned to several subcategories.

Overall, 11 students reported reasons for not using video tutorials. The most important reason for not using video tutorials, reported by 8 students, was lacking need to use them. For example, one student explained “And if I now see ,OK" (...) that are usually the group (...) assignments, if I now see "Ok, I have managed them well", then (...) I do not watch them [the video tutorials] again, extra again. Then, it suffices for me to see again in the sample solution, (...) if I have done it right". In addition, 2 students reported that they had not been aware of the existence of the video tutorials, as is expressed in this exemplary statement: " $I$ have (...) never learned (...) about this [the video tutorials] to tell the truth (...) yes.".

Furthermore, 2 students mentioned other reasons for not using the video tutorials.

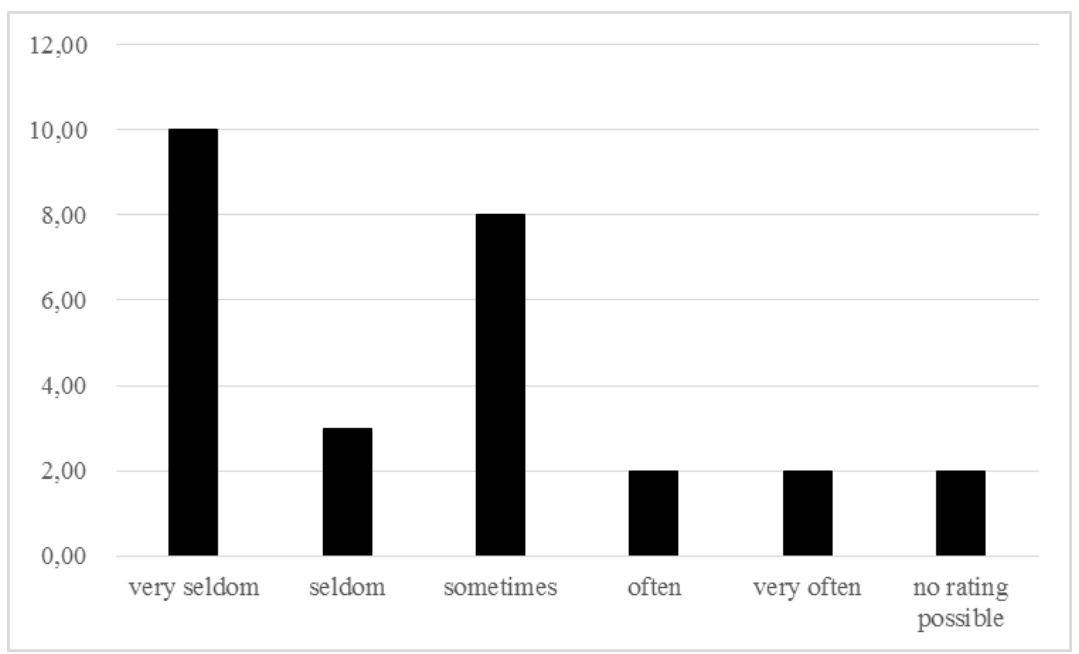

Figure 2. Frequency of using video tutorials. Depicted is the number of participants assigned to the subcategories. Each participant was assigned to one subcategory only. 


\begin{tabular}{|c|c|c|}
\hline $\begin{array}{l}\text { Frequency of using } \\
\text { video tutorials }\end{array}$ & $N(\%)$ & Exemplary statement \\
\hline very seldom & $10(37.0 \%)$ & $\begin{array}{c}\text { "until now in semester XY not yet. I have also } \\
\text { always saved these videos with the current } \\
\text { chapter but (...) I watched only one of them I } \\
\text { believe“. }\end{array}$ \\
\hline seldom & $3(11.1 \%)$ & $\begin{array}{c}\text { "I use them [the video tutorials] seldom, but } \\
\text { sometimes, if I (...) remember it (...) then I just } \\
\text { open it and look through (...)." }\end{array}$ \\
\hline sometimes & $8(29.6 \%)$ & $\begin{array}{l}\text { "I actually watch them [the video tutorials] rather } \\
\text { less during the lecture, but just before the exam } \\
\text { again. That is where (...) a week or two before, } \\
\text { when I am dealing with the topic just then, I } \\
\text { watch it, so that I then see again "Ok, this is how } \\
\text { one solves the problem". }\end{array}$ \\
\hline often & $2(7.4 \%)$ & $\begin{array}{c}\text { "I have used it [the video tutorials] (...) } \\
\text { increasingly. }\end{array}$ \\
\hline very often & $2(7.4 \%)$ & $\begin{array}{c}\text { „Yes, I have actually (...) every time before I did } \\
\text { the assignments, I have watched them [the video } \\
\text { tutorials]" }\end{array}$ \\
\hline no rating possible & $2(7.4 \%)$ & - \\
\hline
\end{tabular}

Table 2. Frequency of using video tutorials. Each participant was assigned to one subcategory only. $N=$ number of participants assigned to the subcategory, $\%=$ Percentage of the sample. $(\ldots)=$ pause, $\mathrm{XY}=$ anonymized.

Table 2 and Figure 2 display the results with respect to research question 2 . The results showed that more than one third of the sample reported using the video tutorials only very seldom. On the other hand, also more than $40 \%$ of the sample reported using the video tutorials at least sometimes.

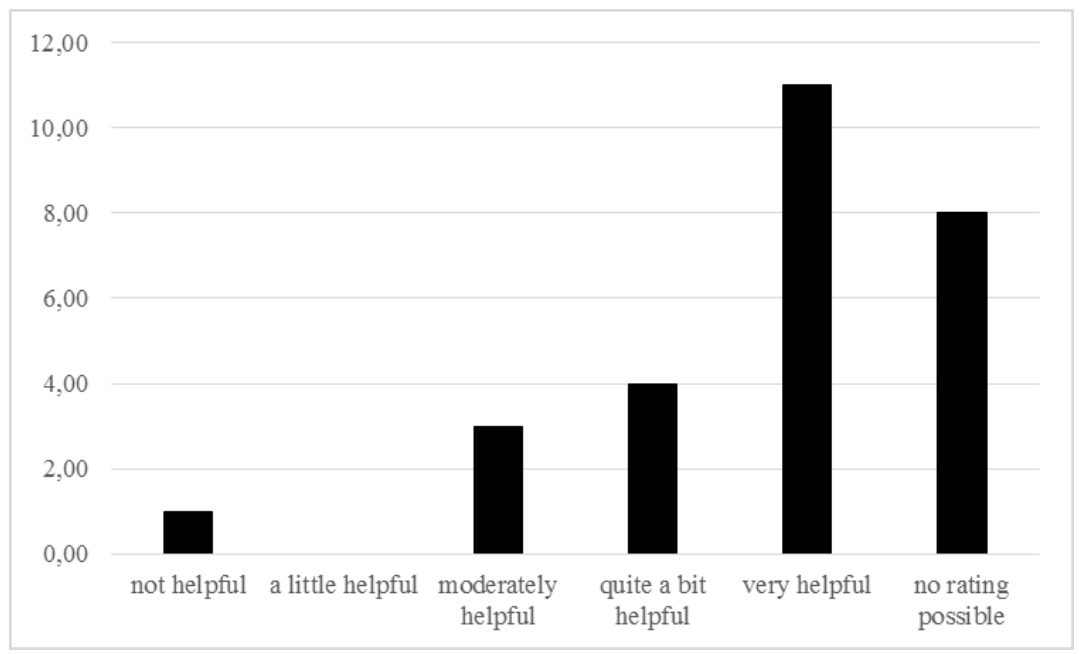

Figure 3. Perceived helpfulness of video tutorials. Depicted is the number of participants assigned to the subcategories. Each participant was assigned to one subcategory only. 


\begin{tabular}{|c|c|c|}
\hline $\begin{array}{l}\text { Helpfulness of } \\
\text { video tutorials }\end{array}$ & $N(\%)$ & Exemplary statement \\
\hline not helpful & $1(3.7 \%)$ & $\begin{array}{l}\text { "Still (...) not for me, for the others (...) it is good because } \\
\text { (...) they (...) probably get (...) some kind of recipe. (...) } \\
\text { And (...) some students want (...) to see how (...) a } \\
\text { mathematics (..) professor correctly works the problem. } \\
\text { (...) Instead of just seeing the sample solution (...) from the } \\
\text { group assignment." }\end{array}$ \\
\hline a little helpful & $0(0.0 \%)$ & 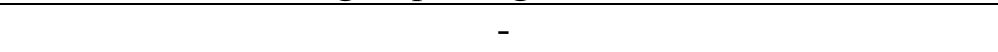 \\
\hline $\begin{array}{l}\text { moderately } \\
\text { helpful }\end{array}$ & $3(11.1 \%)$ & $\begin{array}{l}\text { "moderately helpful, so (...) quite nice, but (...) Just } \\
\text { saying, if one does not have them, one can still accomplish } \\
\text { the exam well, but they are quite nice, so one could (...) } \\
\text { further extend, so that it becomes even more helpful" }\end{array}$ \\
\hline $\begin{array}{l}\text { quite a bit } \\
\text { helpful }\end{array}$ & $4(14.8 \%)$ & $\begin{array}{c}\text { "I thought they were partially very helpful, because } \\
\text { sometimes (...) they were assignments, where one really } \\
\text { (...) thought "(inc.) What? " (laughs) and then (...) when } \\
\text { (inc.) someone then calmly demonstrates the calculation } \\
\text { again" }\end{array}$ \\
\hline very helpful & $\begin{array}{c}11 \\
(40.7 \%)\end{array}$ & $\begin{array}{l}\text { "so, they were (...) very sensible, because they (...) } \\
\text { especially for the practice problems during exam } \\
\text { preparation (...) provided solutions to some assignments, } \\
\text { so that one could (...) control a little bit. (...) And yes, on } \\
\text { the other hand (..) they [the video tutorials] explain } \\
\text { sample mathematics problem very well one time. (...) And } \\
\text { (...) yes, this was (...) very useful" }\end{array}$ \\
\hline $\begin{array}{l}\text { no rating } \\
\text { possible }\end{array}$ & $8(29.6 \%)$ & - \\
\hline
\end{tabular}

Table 3. Perceived helpfulness of video tutorials. Each participant was assigned to one subcategory only. $N=$ number of participants assigned to the subcategory. $\%=$ Percentage of the sample, (...) pause, $\mathrm{XY}=$ anonymized, (inc.) $=$ incomprehensible.

With respect to research question 3, as can be seen in Table 3 and Figure 3, the analysis showed that the overall perceived helpfulness of the video tutorials was high. Unfortunately, for about $30 \%$ of participants (mostly those indicating to never have used the video tutorials), no rating could be made concerning their perceived helpfulness. Among those whose answers could be classified however, an overwhelming majority claimed the video tutorials to be helpful or very helpful.

Discussion

The current study took a qualitative approach to examine engineering students' use of and satisfaction with video tutorials in a mathematics course at a technical university in Germany. In summary, the results of the study showed that engineering students made use of these videos and appreciated them highly. Although the results concerning the frequency of use suggest that the overall use of the video tutorials was not excessive (with only about $15 \%$ 
using the video tutorials often or very often), these results need to be considered in light of the purposes for which students used them. That is, students reported using video tutorials selectively: Exam preparation was the most important purpose for which students used the video tutorials, followed by understanding of topics and problem solving methods and mathematics problems assigned. These results are in line with previous studies ${ }^{3,5}$. Furthermore, the study showed a high degree of satisfaction with the video tutorials among students. Thus, the study adds to a variety of studies which showed students to be highly satisfied with online learning resources in general (e.g. lecture recordings ${ }^{13}$ ) and video tutorials in particular ${ }^{5,6}$.

Nonetheless, the current study had some limitations which need to be considered. The sample was small and consisted of volunteers from one course, university and country, which limits the generalizability of the results. The fact that the results were consistent with previous research conducted in different environments however supports their validity. Furthermore, the qualitative approach made it a) difficult to use a bigger sample given the existing resources and b) places more importance on sample composition than sample size.

Nonetheless, at present, it needs to be kept in mind that the research questions can be answered only with respect to the particular course in which the current study was conducted. The results do however provide a basis for future studies which can benefit from the issues explored in the current study. Besides using broader and bigger samples in order to be able to assess potential effects of the learning environment (including the lecturer, course, institution and culture) directly, future studies should also adopt different methodological approaches. For example, the frequency of use and perceived helpfulness of video tutorials (i.e. research question 2 and 3) would have better been assessed using a Likert-scale questionnaire. Even more, especially with respect to the frequency of use, it would have been enriching to receive more detailed and quantitative information, such as the number of hours or number of times students spent watching the video tutorials. Assessing such information or using a Likertscale questionnaire was not possible in the current study due to external circumstances. It would be very valuable if future studies realized such research designs. As an additional limitation to be noted, the current study was completely based on students' self-reports. Future studies should try to include other data sources, in particular when examining the frequency of use of video tutorials (e.g. by assessing the number of downloads or online views of the tutorials).

Despite these limitations, the results are of importance for both researchers and practitioners in the field of mathematics education for engineering students. With respect to mathematics education research, the results demonstrate that taking a qualitative approach to investigating students' use of and satisfaction with learning resources provides valuable results and thus, is worth the effort and resources needed. Furthermore, the study contributes to leveling an imbalance between research and practice: Considering that online resources have been widely used in mathematics education for years, there is surprisingly little research investigating their acceptance by students ${ }^{14}$, especially when narrowing the focus down to engineering students. For practitioners, the results provide additional motivation to invest effort and time into the creation of video tutorials for mathematics courses. 
To conclude, the current study underscored the value of enriching mathematics courses for engineering students through video tutorials. Knowing which learning resources students value and how (intensively) they use them is of crucial importance for improving mathematics education - especially in the light of the importance of mathematics education for engineering students ${ }^{15}$ as well as the difficulties of engineering students with mathematics ${ }^{1,2}$ on the one hand and decreasing resources for faculties and institutions on the other hand. Future studies could further enrich knowledge on this topic by taking different methodological approaches and considering diverse samples. Furthermore, there are many other promising avenues for future research. For example, the author is currently investigating for which topics in particular students demand and appreciate video tutorials. Other questions for future research include potential effects of the narrator or creator of video tutorials (e.g. gender, status, etc.), specific elements of video tutorials which influence students' use and evaluation and differential use of video tutorials among different subgroups of students (e.g. by gender, age etc.).

References

[1] H. Dehling, E. Glasmachers, B. Griese, J. Härterich, and M. Kallweit, "MP² Mathe/plus/Praxis: Strategien zur Vorbeugung gegen Studienabbruch," ZFHE, vol. 9, no. 4, pp. 39-56, 2014.

[2] M. W. Ohland, A. G. Yuhasz, and B. L. Sill, "Identifying and removing a Calculus prerequisite as a bottleneck in Clemson's General Engineering Curriculum," Journal of Engineering Education, vol. 93, no. 3, pp. 253-257, 2004.

[3] C. McLoughlin and B. Loch, "Building cognitive bridges in Mathematics: Exploring the role of screencasting in scaffolding flexible learning and engagement," in Show me the Learning. Proceedings ASCILITE 2016 Adelaide, ASCILITE $33^{\text {rd }}$ International Conference of Innovation, Practice and Research in the Use of Educational

Technologies in Tertiary Education 2016, Adelaide, Australia, November 27-30, 2016, S. Barker, S. Dawson, A. Pardo, C. Colvin, Eds. pp. 412-420.

[4] M. Anastasakis, C. L. Robinson, and S. Lerman, "Links between students' goals and their choice of educational resources in undergraduate mathematics," Teaching Mathematics and its Applications: An International Journal of the IMA, vol. 36, no. 2, pp. 67-80, 2017.

[5] T. B. T. Ahmad, F. Doheny, S. Faherty, and N. Harding, "How instructor-developed screencasts benefit college students' learning of maths: Insights from an Irish case study," The Malaysian Online Journal of Educational Technology, vol. 1, no. 4, pp. 12-25, 2013.

[6] R. Kay and I. Kletskin, "Evaluating the use of problem-based video podcasts to teach Mathematics in higher education," Computers \& Education, vol. 59, no. 2, pp. 619627, 2012.

[7] C. Ní Shé, C. Mac an Bhaird, E. Ní Fhloinn, and A. O’Shea, "Students' and lecturers' views on Mathematics resources," Teaching Mathematics and its Applications: An International Journal of the IMA, vol. 36, no. 4, pp. 183-199, 2017.

[8] B. Loch, O. Gill, and T. Croft, "Complementing Mathematics support with online MathsCasts," ANZIAM Journal, vol. 53, pp. 561-575, 2012. 
[9] Statistisches Bundesamt, "Studierende an Hochschulen - Vorbericht - Fachserie 11 Reihe 4.1 - Wintersemester 2016/2017," Statistisches Bundesamt (Destatis), 2017.

[10] T. Dresing and T. Pehl, Praxisbuch Interview, Transkription \& Analyse. Anleitungen und Regelsysteme für qualitativ Forschende. Marburg: Dr. Dresing und Pehl GmbH, 2015. [Online]. Available.

[11] U. Kuckartz, T. Dresing, S. Rädiker, and C. Stefer, Qualitative Evaluation: Der Einstieg in die Praxis, 2., aktualisierte Aufl. ed. Wiesbaden: VS, Verlag für Sozialwissenschaften, 2008.

[12] U. Kuckartz, Qualitative Inhaltsanalyse: Methoden, Praxis, Computerunterstützung, 3., überarbeitete Auflage ed. (Grundlagentexte Methoden). Weinheim; Basel: Beltz Juventa, 2016.

[13] J. Copley, "Audio and video podcasts of lectures for campus-based students: production and evaluation of student use," Innovations in Education and Teaching International, vol. 44, no. 4, pp. 387-399, 2007.

[14] S. A. Lloyd and C. L. Robertson, "Screencast tutorials enhance student learning of statistics," Teaching of Psychology, vol. 39, no. 1, pp. 67-71, 2012.

[15] F. Rønning, "Future teaching of mathematics for engineers," in Proceedings from $42^{\text {nd }}$ SEFI Annual Conference, $42^{\text {nd }}$ SEFI Annual Conference 2014, Birmingham, UK, 1519 September, 2014. 2014. 